EPJ Web of Conferences 98, 04004 (2015)

DOI: $10.1051 /$ epjconf/ 20159804004

(C) Owned by the authors, published by EDP Sciences - SIF, 2015

\title{
Geothermal energy
}

\author{
A. Manzella
}

Institute of Geosciences and Earth Resources - Pisa, Italy

\begin{abstract}
Summary. - Geothermal technologies use renewable energy resources to generate electricity and direct use of heat while producing very low levels of greenhouse-gas (GHG) emissions. Geothermal energy is stored in rocks and in fluids circulating in the underground. Electricity generation usually requires geothermal resources temperatures of over $100^{\circ} \mathrm{C}$. For heating, geothermal resources spanning a wider range of temperatures can be used in applications such as space and district heating (and cooling, with proper technology), spa and swimming pool heating, greenhouse and soil heating, aquaculture pond heating, industrial process heating and snow melting. Geothermal technology, which has focused so far on extracting naturally heated steam or hot water from natural hydrothermal reservoirs, is developing to more advanced techniques to exploit the heat also where underground fluids are scarce and to use the Earth as a potential energy battery, by storing heat. The success of the research will enable energy recovery and utilization from a much larger fraction of the accessible thermal energy in the Earth's crust.
\end{abstract}

\section{1. - Introduction}

Geothermal technologies use the heat contained in the ground. In its broad term the geothermal energy is the thermal energy contained in our planet, the Earth. In this document we will restrict our attention to the practical use for mankind, i.e. the heat that can be extracted from a depth up to about $10 \mathrm{~km}$, which is the maximum depth reached

This is an Open Access article distributed under the terms of the Creative Commons Attribution License 4.0, which permits unrestricted use, distribution, and reproduction in any medium, provided the original work is properly cited. 


\section{EPJ Web of Conferences}

by human drilling. In this thin portion of Earth heat is inexhaustible, since it moves from the Earth's interior towards the surface, where it dissipates. Part of this heat derives from the slow cooling from primordial heat, involved in the Earth's formation, and part derives from the decay of long-living radioactive isotopes contained by crustal rock minerals. The most abundant isotopes having a half-life comparable to the age of the Earth, so that they can still be significant heat producers, are ${ }^{40} \mathrm{~K},{ }^{232} \mathrm{Th},{ }^{235} \mathrm{U}$ and ${ }^{238} \mathrm{U}$. The amount of heat that is released to the space from the interior through a unit area in a unit of time, the Earth's heat flow, varies from place to place and with time, depending on the geological and therefore physical condition of the underground. On average, the heat flow from the continental crust is $57 \mathrm{~mW} / \mathrm{m}^{2}$ and from the oceanic crust is $99 \mathrm{~mW} / \mathrm{m}^{2}$ [2]. Our planet is a dynamic system, with its inner changes, mostly slow from the perspective of human time, but producing very quick changes close to the surface. These are not only earthquakes and volcanic eruptions, very well-known to humans. The interaction of inner, geological processes with the physical processes just above the ground surface originates the complex system characterizing the geothermal systems. The hottest areas of the Earth's surface are near tectonic plate boundaries, which are often associated also to volcanoes and seismic activity and where hot magmatic bodies are present within or close to our reference $10 \mathrm{~km}$ depth. The heat flow at the Earth's surface therefore derives from the radiogenic decay within the upper crust, the heat generated in the most recent magmatic episode, and the heat coming from the mantle and inner Earth's structures. In continental crust, where the isotope heating is larger since granitic rocks rich of long-living radioactive isotopes are common, the heat flow is highest in areas having experienced "recent" (less than 65 million year) magmatic activity, whereas it decreases to $46 \mathrm{~mW} / \mathrm{m}^{2}$ in crust older than 800 million years [2]. In oceanic crust the concentration of radiogenic heating is negligible due to the rock composition (basaltic), but the crust thickness is smaller than in continents and the heat flow largely derives from heat flowing from the mantle. Most plate boundaries are below sea level and the young oceanic crust has very high heat flow values. Geothermal exploitation is focused so far to continental areas, where energy is requested.

To extract energy from the underground we mostly use the water as carrier of heat. As the crust is highly fractured and thus permeable to fluids, surface water, essentially rainwater, penetrates at depth and exchanges heat with the rocks. Two main forms of heat transfer occur within the crust: conduction and convection. Where rocks are very fractured and circulating fluids are abundant, the resulting convective heat transfer is very efficient and can be easily exploited by drilling wells and discharge the hot fluids to the surface. In these convective systems, named hydrothermal resources, the aquifers represent the geothermal reservoir. Occasionally, in areas of very high heat flow, the fluid has high temperature (up to above $300^{\circ} \mathrm{C}$ ) and, depending on the pressure, can be vapor (steam) or water.

Warm and hot fluids can be extracted from the underground in a wide range of temperature and discharge rate, and used directly for their heat content or to produce electric power. Even the modest temperatures found at shallower depths can be used to extract or store heat by means of ground source heat pumps, that are nowadays a widespread application for geothermal energy. 
Geothermal technologies described in the following sections, while producing very low levels of greenhouse-gas (GHG) emissions, have an important role to play in realizing targets in energy security, economic development and mitigating climate change. Geothermal resources, as opposed to hydrocarbon ones, are generally renewable since the circulation of heat and fluid is continuous. There is a constant terrestrial heat flow to the surface, then to the atmosphere from the immense heat stored within the Earth, and fluid enters the reservoir from the recharge zones or injected in the subsurface through injection wells (in industrial plants). Heat can be extracted at different rates. To guarantee a sustainable use of geothermal energy, the rate of consumption should not exceed the rate of generation, so that the heat removed from the resource is replaced on a similar time scale. Geothermal plants typically develop below a certain level of energy production.

Geothermal typically provides base-load generation, since it is generally immune from weather and seasonal variation, therefore producing almost constantly and distinguishing it from several other renewable technologies that produce variable power or heat with time.

\section{2. - Utilization of geothermal heat}

In direct use geothermal energy is employed directly as heat without further conversion into other types of energy. Direct use of geothermal heat and water dates back thousands of years and it continues today. The Romans, Chinese, and Native Americans left clear proofs that they used geothermal water for bathing, cooking and for therapeutic purposes. Where accessible, natural hot waters have been used for space heating in cold areas and seasons. Today geothermal water is used for many different applications depending on the temperature of the water, including electricity generation, which is the most important form of utilization of high-temperature geothermal resources $\left(>120^{\circ} \mathrm{C}\right)$. Known uses of geothermal heat range from fish farming and soil heating at low temperatures, through space heating and drying at intermediate temperatures, to industrial processing at high temperatures (they have a wide temperature range).

Heat demand represents a significant share of final energy consumption for space heating, especially in cold countries, agricultural and industrial processes. Geothermal heat production systems may meet the demand simply providing fluids at the required temperature. For example, the water circulating through the network of pipes, beams and panels of the heating systems of a building may be kept constant in the summer by exchanging heat with groundwater fluids at a temperature of $18^{\circ} \mathrm{C}$. If groundwater fluid temperature of $30^{\circ} \mathrm{C}$ is discharged, it can be used to pasteurize milk in a cheese factory. This passive or "free" heating and cooling (H\&C) is one of the most environmental friendly forms of $\mathrm{H} \& \mathrm{C}$ available, and the base of most of the direct use of geothermal heat till recently. But passive use has a limitation: it must adapt to the temperature of natural groundwater available, which is not always what we need. Thanks to improvements of absorption machines and heat pumps, which are readily available on the market and efficiently able to heat and cool the fluids, geothermal applications are becoming more and more flexible. 


\section{EPJ Web of Conferences}

Geothermal heat pump systems for the moment are a reference market mostly dedicated to space heating and cooling, and exploits groundwater or groundcoupled temperatures at shallow depth (10-200 $\mathrm{m}$ depth). Since they do not require any particular thermal anomaly, geothermal heat pumps represent a geothermal heat production technology which is suitable even for regions with altogether ordinary geothermal conditions. Thanks to them, nowadays direct use of geothermal heat can be done anywhere in the world, and many countries which are not specially known for geothermal resources have been ranking high in geothermal direct utilization due to the use of geothermal heat pumps. Since this technology has a large potential of expanding its application and may be combined with other geothermal technologies, we describe it in some detail.

$\mathbf{2} 1$. Geothermal heat pump technology. - To heat or cool a space we need to transfer heat. To this aim, we may use the thermal energy stored in the ground at shallow depth, usually $50-100 \mathrm{~m}$ to a maximum of $250 \mathrm{~m}$. Below a depth of a few meters the temperature is not affected by the seasonal change of air temperature and is essentially constant and equal to the mean annual air temperature. The thermal energy of the ground can be exploited by using heat pumps, which convert the low-temperature geothermal energy to thermal energy at a higher temperature exploiting the physical property of fluids to absorb and release heat when they vaporize or condense, respectively. They work like a refrigerator, moving heat from a space (to keep it cool) and discharging heat at higher temperature. They are made of a closed circuit where a refrigerant fluid is circulated, usually water or other kind of fluids not dangerous for the environment. Depending on temperature and pressure condition the refrigerant fluid is in the liquid or vapor state, and is compressed or expanded by using an external energy, usually electric, to move the heat. Common air conditioning systems work this way and exchange heat with the external air.

In the Ground Source Heat Pumps (GSHP) the refrigerant fluid exchange heat with the ground, taking advantage of the fact that the ground has a stable temperature throughout the year. In winter, when the external air is cold, the ground has a higher temperature and the heat exchange is more efficient. With proper technology the process may be reversed, and the heat pump may also work as a refrigerator in summer, using the cool temperature of the ground to chill the space. The main component added is the underground heat exchanger, through which the heat is absorbed or released to the ground.

There are two main kinds of GSHP: the open and close loop systems (fig. 1). Open systems physically abstract water from the source. Groundwater is abstracted (usually pumped) from springs, drilled boreholes or flooded mines. In closed loop systems a carrier fluid circulates in a closed loop of pipe buried underground and is not in direct contact with the ground or rock. The latter is often called subsurface heat exchanger or geoexchanger.

The open loop systems are made of a heat exchanger (in the building to be heated/ cooled), an abstraction well, an injection well (fig. 2). In some cases the abstracted water is not re-injected in the ground but released at the surface (in sewage systems, for example), thus avoiding the cost of a second borehole. This practice is recommended 

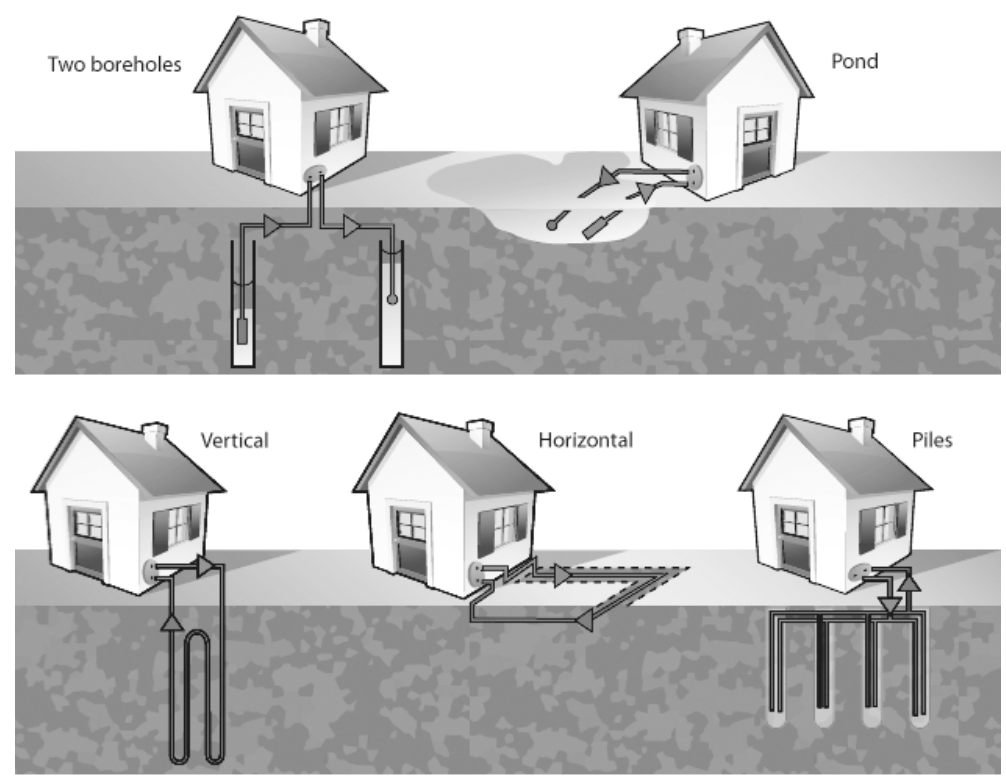

Fig. 1. - Open (top) and closed (bottom) loop GSHP systems.

only when there is no risk of reducing the groundwater in the aquifer, and should be done with the proper care for avoiding environmental impact. Re-injection of abstracted water is also regulated by local laws, which defines limitations of use.

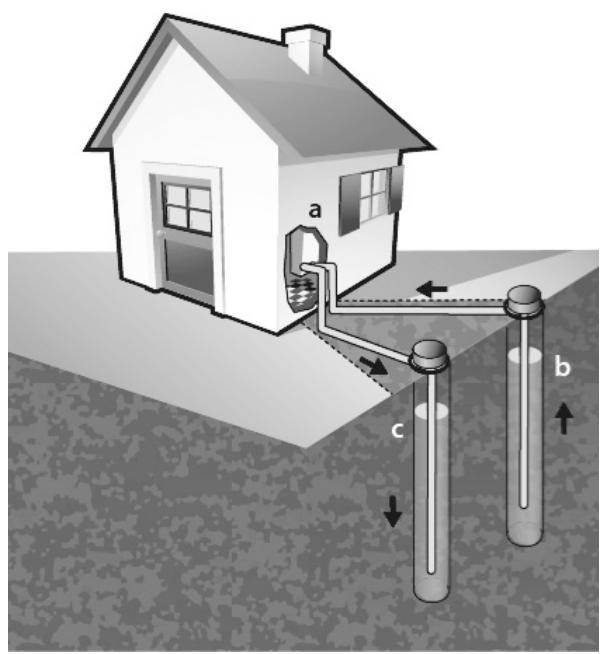

Fig. 2. - Open loop GSHP system in detail: a) heat exchanger; b) abstraction well; c) injection well. 


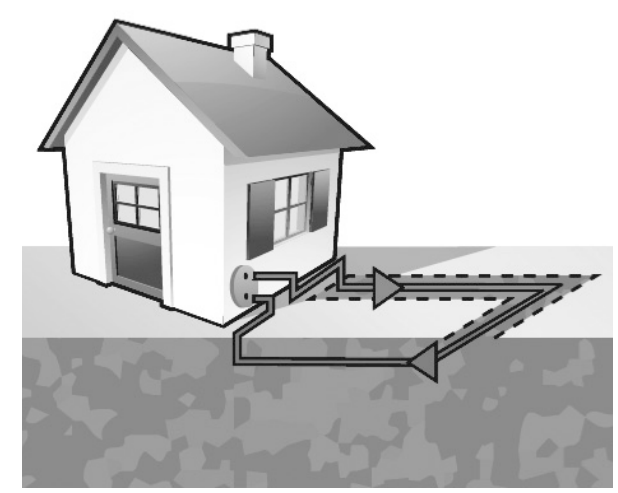

Fig. 3. - Closed loop GSHP, horizontal linear system.

The amount of water to abstract, the rate of abstraction and the distance between the two wells must be properly planned. They depend on the heat demand and on the thermal and hydraulic properties of the ground. Accurate planning avoids to cool (or heat in summer) the ground at a higher rate than natural equilibrium allows, therefore guaranteeing the sustainability of the systems and the thermal balance in the aquifer. The balance is enhanced when the system works in reverse mode, i.e. heating in winter (chilling the ground) and cooling in summer (heating the ground). Abstraction and injection wells should be far enough to avoid thermal short circuiting between the two during the installation's life time, commonly 20-30 years.

The open systems have the advantage of using natural water, and may be used also for "free" (natural) cooling or for drinking, watering depending on its quality. Moreover, they absorb more heat from the ground than a geoexchanger of the same size, and for equal heat demand they cost less since they require less drilling.

The closed loop or Ground Coupled Heat Pump (GCHP) systems are made of closed loop tubing that can be installed horizontally as a loop field in trenches, vertically in wells or as baskets (figs. 3, 4 and 5). The loop is typically made of high-density polyethylene pipe and contains a mixture of water and anti-freeze. The size of the loop field depends on the soil type and moisture content, the average ground temperature and the heat loss or gain characteristics of the building being conditioned. Horizontal loops can be used wherever there is sufficient surface area available for their installation, and are more rarely installed for space heating and cooling of buildings than vertical borehole heat exchangers. Vertical exchanger commonly consist of one or several U-pipes or coaxial pipes, more frequently used for deeper boreholes. Bore-holes are spaced at least 5-6 m apart and the depth depends on ground and building characteristics. For example, a house needing $10 \mathrm{~kW}$ of heating capacity might need three boreholes $80-110 \mathrm{~m}$ deep in sedimentary rocks. Heat exchanger pipe systems can be integrated directly into the concrete foundations of buildings and other constructions for heating and cooling and are called heat piles. If properly designed and integrated into a combined heating and 


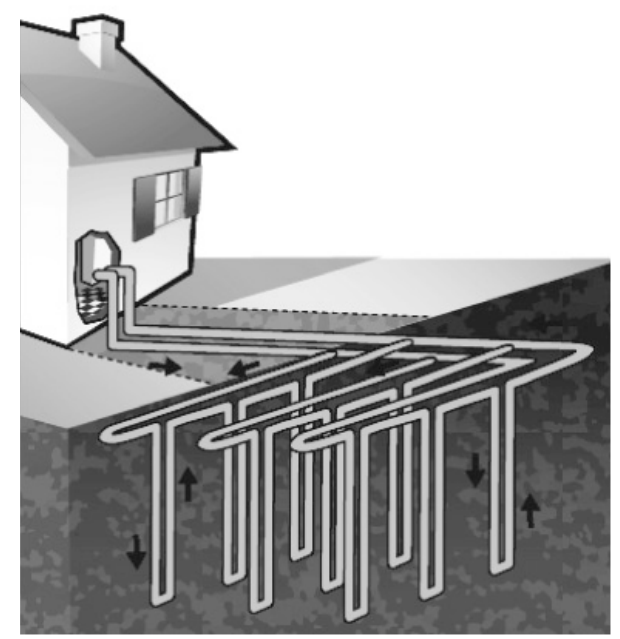

Fig. 4. - Closed loop GSHP, vertical system.

cooling system right from the beginning, these systems can be a useful part of modern low-energy, low $\mathrm{CO}_{2}$-emission buildings and constructions.

The net thermal efficiency of a heat pump should take into account the efficiency of electricity generation and transmission, typically about $30 \%$. Since a heat pump moves 3 to 5 times more heat energy than the electric energy it consumes, the total energy output is much greater than the electrical input. This results in net thermal efficiencies greater than $300 \%$ as compared to radiant electric heat being $100 \%$ efficient. Traditional combustion furnaces and electric heaters can never exceed $100 \%$ efficiency.

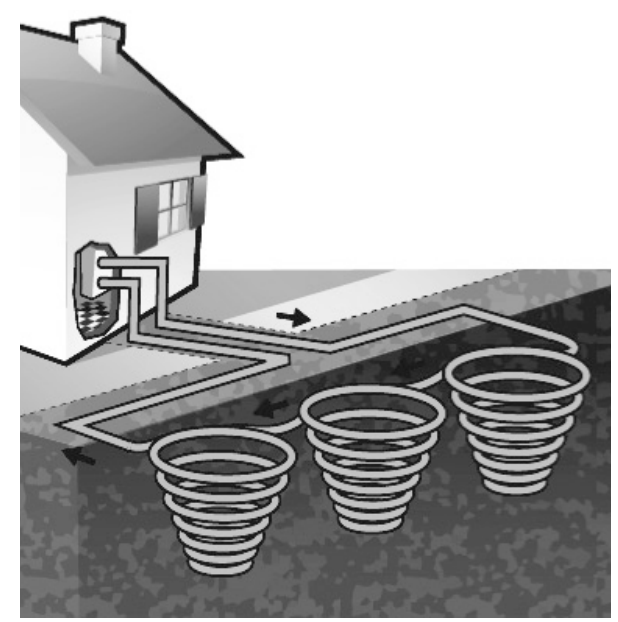

Fig. 5. - Closed loop GSHP, basket system. 


\section{EPJ Web of Conferences}

Geothermal heat pumps can reduce energy consumption - and corresponding air pollution emissions - up to $44 \%$ compared to air source heat pumps and up to $72 \%$ compared to electric resistance heating with standard air-conditioning equipment. The performance of heat pumps is usually expressed as Coefficient of Performance (COP), which is the ratio of heating output or heat removal to electricity input. Cooling performance is typically expressed as the Energy Efficiency Ratio (EER) while heating and cooling performance of reversal heat pumps is typically expressed as the Seasonal Performance Factor (SPF), the mean of COP and EER.

Performance is influenced by all components of the installed system, including the soil conditions, the ground-coupled heat exchanger, the heat pump appliance, and the building distribution, but is largely determined by the difference between the input (ground) temperature and the output (room) temperature. GSHP on the market today have standard COP ranging from 2.4 to 5.0 and EER ranging from 10.6 to 30 [7].

Geothermal heat pump technology is used for space heating and cooling of single building, small and large, and in district heating systems. Ground source heat pumps are characterized by high capital costs and low operational costs compared to other conventional heating source. Since the overall economic benefit depends primarily on the relative costs of electricity and fuels, which are highly variable over time and across the world, a constant and overall estimate is not possible. Based on recent prices, ground source heat pumps have lower operational costs than any other conventional heating source except natural gas and almost everywhere in the world, excluding a handful of countries where natural gas is exceptionally cheap, or where electricity is exceptionally expensive. Capital costs, which may amount to 10-15 thousands of US\$ for a single home system, are known to benefit from economies of scale so they are more cost-effective for larger commercial buildings and harsher climates. The cost of installation, which can be two to five times that of a conventional heating system in most residential applications, is affected by the size of living area, the home's age, insulation characteristics, the geology of the area, and location of the property. Although ground source heat pumps are recognized as one of the most efficient heating and cooling systems on the market, they are known and advertised only in some countries, and seldom benefit from tariffs and incentives helping to sustain the capital cost and based on metered readings on an annual basis for 1 or 2 decades.

Technological frontiers in the geothermal heat pump sector are dedicated to the optimization of seasonal thermal energy storage and interseasonal heat transfer. The heat captured and stored in thermal banks in the summer can be retrieved efficiently in the winter. The Underground Thermal Energy Storage (UTES) concept goes beyond the geothermal energy and consider the storage of thermal energy produced by solar source or waste heat from industrial processes, for example. UTES can be closed (Borehole Thermal Energy Storage, BTES) or open systems (Aquifer Thermal Energy Storage, ATES), as for GSHP technology. Heat storage efficiency increases with scale, so this advantage is most significant in commercial or district heating systems.

Other technological frontiers refer to optimization of process technology of heat 


\section{LNES 2014}

pumps, such as for the absorption heat pump, and the combination of geothermal and other renewable energy technologies for heating and cooling.

$\mathbf{2} 2$. Technology for direct use of heat. - A variety of processes requires a temperature comparable to that of available geothermal fluids. The warm water circulating in pipes and appliances for providing heat to these processes is conventionally heated with a boiler, using gas or other fossil fuels as energy source. When geothermal fluids are used, they can be directly circulated in the heating system or, more frequently, clean water is heated through a heat exchanger and then circulated, while geothermal fluids are re-injected in the subsurface.

The use of geothermal heat not only increases the share of green energy and reduces GHG emissions, but on the long term it also contributes to the energy efficiency of the plant since it forces the dimensioning of the heating system to the true temperature level required by the process. Most heating systems are dimensioned for very high temperature waters, easily obtainable by boilers but not with geothermal. It has not been easy or convenient to adapt an existing heating system to a geothermal exchange system, and most of reported geothermal direct use plants were designed as geothermal since the beginning. Thanks to heat pump technology we have now much more flexibility.

The main types of direct applications of geothermal energy are space heating (including heat pumps described before), bathing and swimming (including balneology), agricultural (greenhouses and soil heating), industry, and aquaculture (mainly fish farming). In Europe the main share of installed thermal potential is for geothermal heat pump system (68\%) and district heating (15\%), while balneology, aquaculture and deicing amount to $11 \%$ and industrial and agricultural processes to $6 \%$ [1]. There are many other types of utilization, on a much smaller scale, some of which are unusual and seldom reported.

Space and district heating and cooling has its most important expression in Iceland, where over $98 \%$ of space heating is provided by geothermal. It is also widely distributed in the East European (Pannonian) countries, as well as in the United States, China, Japan, France (Paris basin).

Geothermal district heating (GDH) systems are capital intensive. The main costs are initial investment costs for production and injection wells, and down-hole pumps. These costs add to the high cost of conventional district systems, for transmission pumps, pipelines and distribution networks, monitoring and control equipment, peaking stations and storage tanks. Operating expenses, however, are comparatively lower than in conventional systems, and consist of pumping power, system maintenance, control and management. An important benefit is achieved by combining heating and cooling in areas where the climate permits it, since the load factor would be higher than the factor for heating alone, and the unit energy price would consequently improve. The distribution network is particularly expensive, and a crucial factor in estimating the initial cost of the system is the thermal load density, which is the heating and cooling demand divided by the ground area of the district. A high heating and cooling demand density determines the economic feasibility of a geothermal district heating project. 


\section{EPJ Web of Conferences}

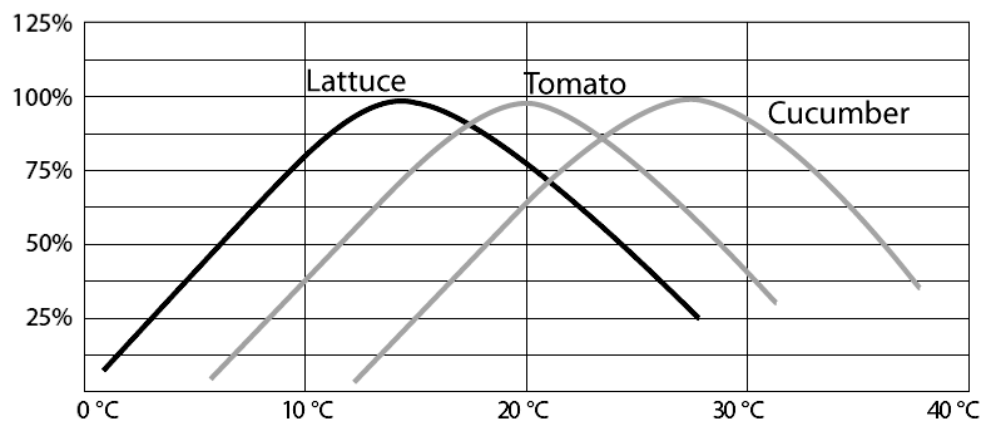

Fig. 6. - Productive trend with temperature of common vegetables.

In Europe there is an increasing interest in GDH systems. Of the about 5000 district heating systems of Europe, 237 are GDH (197 in EU-28) and cover about the $10 \%$ of heat market, with a total thermal capacity of $4.3 \mathrm{GW}$ and about $12883 \mathrm{GWh}$ of production [3].

The agricultural applications of geothermal fluids consist of the plant growing temperature control in open fields and greenhouses. Thermal water can be used in open-field agriculture to heat the soil and, sometime, to irrigate it where ponds and rivers are not available. Soil heating is provided by burying thin pipelines where warm fluids are circulated. The greatest drawback in this heating is the cost, and this technique results economic only in few cases. Heating the soil in buried pipelines without the irrigation system could also decrease the heat conductivity of the soil, because of the drop in humidity around the pipes, and consequent thermal insulation. The best solution seems to be that of combining soil heating and irrigation. The chemical composition of the geothermal waters used in irrigation must be monitored carefully to avoid adverse effects on the plants. The temperature control in open-field agriculture prevents any damage ensuing from low environmental temperatures, extends the growing season, increases plant growth, and boosts production. It also sterilizes the soil, increasing productivity.

The most common application of geothermal energy in agriculture is, however, in greenhouse heating, which has been developed on a large scale in many countries. The greenhouse heating extends the cultivation of vegetables and flowers out-of-season or in an unnatural climate, and can now draw on a widely experimented technology. Various solutions are available for achieving optimum growth conditions, based on the optimum growth temperature of each plant (fig. 6), and on the quantity of light, on the $\mathrm{CO}_{2}$ concentration in the greenhouse environment, on the humidity of the soil and air, and on air movement. Greenhouse heating can be accomplished by forced circulation of air in heat exchangers, hot-water circulating pipes or ducts located in or on the floor, finned units located along the walls and under benches, or a combination of these methods.

Operating costs of greenhouse heating, which in some cases account for $35 \%$ of the product costs (vegetables, flowers, house-plants and tree seedlings), can be considerably reduced by geothermal heat. This is the case in particular when geothermal fluids naturally flow at the surface and abstraction pumps are not required. Geothermal brines 
LNES 2014

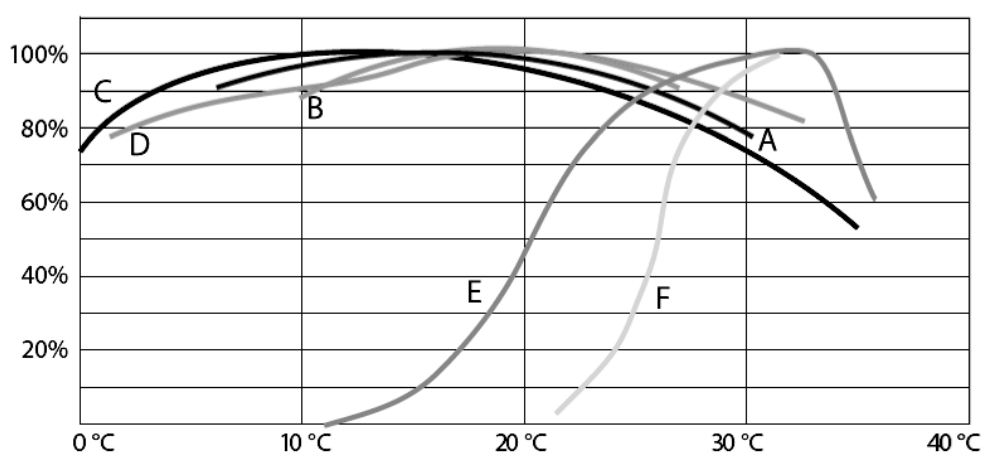

Fig. 7. - Productive trend with temperature of different animal species. $\mathrm{A}=$ chicken, egg production; $\mathrm{B}=$ poultry, weight increase; $\mathrm{C}=$ Jersey cow, milk production; $\mathrm{D}=$ pork, weight increase; $\mathrm{E}=$ shrimps, weight increase $\mathrm{F}=$ cat-fish, weight increase.

often require treatment, since their chemical composition may produce deposits in the pipes, pumps and heat exchanger plates.

This technology has taken maximum advantage from heat pump technology, and shallow groundwater or ground energy is more and more used. In the Netherlands, for examples, there has been a major boost of local tomato production thanks to the geothermal technology.

Farm animals and aquatic species, like vegetables and plants, benefit in quality and quantity from the optimum conditioning of their environmental temperature (fig. 7). Geothermal heat is used profitably in animal husbandry. The energy required to heat a breeding installation is about $50 \%$ of that required for a greenhouse of the same surface area, so a cascade utilization could be adopted. Breeding in a temperature-controlled environment improves farm animal health, and the hot fluids can also be used to clean, sanitize and dry the animal shelters and waste products. Aquaculture, the controlled breeding of aquatic forms of life, is the most common application of geothermal animal husbandry, due to an increasing market demand and the large importance of the breeding temperatures for aquatic species with respect to land species, as can be seen in fig. 7 . By maintaining an optimum temperature artificially we can breed more exotic species, improve production and even, in some cases, double the reproductive cycle. The species that are typically raised are carp, catfish, bass, tilapia, mullet, eels, salmon, sturgeon, shrimp, lobster, crayfish, crabs, oysters, clams, scallops, mussels and abalone. Aquaculture also includes alligator and crocodile breeding, as tourist attractions and for their skins, which could prove a lucrative activity.

The temperatures required for aquatic species are generally in the $20-30{ }^{\circ} \mathrm{C}$ range. The size of the installation will depend on the temperature of the geothermal source, the temperature required in the fish ponds and the heat losses from the latter.

Geothermal energy has been used successfully to provide the heat needed to grow Spirulina throughout the year in temperate countries. This is a single-celled, spiral-shaped, blue-green micro-alga, in the past called "super-food" because of its nutrient density, 


\section{EPJ Web of Conferences}

although at the moment it is being marketed as a nutritional food supplement. Spirulina is being farmed in a number of tropical and sub-tropical countries, in lakes or artificial basins, where conditions are ideal for its fast and widespread growth (a hot, alkaline environment rich in $\mathrm{CO}_{2}$ ).

Industrial applications, including process heating, evaporation, drying, distillation, sterilization, washing, de-icing, and salt extraction are reported so far in 14 countries, where the installations tend to be large and energy consumption high. Examples of application also include bottling of water and carbonated drinks, paper and vehicle parts production, oil recovery, food processing and milk pasteurization, leather industry, chemical extraction, $\mathrm{CO}_{2}$ extraction, laundry use, pulp and paper processing, and borate and boric acid production. The best example in the world of industrial applications are the diatomaceous drying in Námafjall (Iceland), pulp and paper processing at Kawerau (New Zealand), and the 50 years old industry of milk products Medo-Bel Creamery of Klamath Falls (Oregon). Desalination using geothermal heat has been proposed in many places, mainly volcanic island, for solving a typical problem of lack of drinking water in tourist season in remote island. It has never proved to be economical and the proposals never reached the stage of demonstration but, with the help of heat pumps, the plants might see a growing application in the future. More and more wineries are adopting geothermal systems for temperature control of the various phases of wine production, especially now that heat pumps technology contributes also to humidity control.

The elements to consider in the cost estimate of a geothermal system for heat application are numerous and often more complicated than for other forms of energy. Plant installation and operating cost must be evaluated carefully before a geothermal project is launched, and vary from case to case. The overall cost depends on the resource (amount of heat, fluid discharge rate, depth to drill), the cost of installation and operation, and financial conditions including available tariffs and incentives, the price of other available energy sources, the plant efficiency, the load time. District space heating levelized costs range from US\$ $45 / \mathrm{MWh}_{\mathrm{t}}$ to US\$ $85 / \mathrm{MWh}_{\mathrm{t}}$. Costs of heating greenhouses vary between $\mathrm{US} \$ 40 / \mathrm{MWh}_{\mathrm{t}}$ and $\mathrm{US} \$ 50 / \mathrm{MWh}_{\mathrm{t}}[5]$.

\section{3. - Power production}

Electricity generation mainly needs steam to rotate a turbine that activates a generator, which produces electricity. Most power plants still use fossil fuels to boil water for steam, whereas geothermal power plants use steam produced from or heated by underground hot fluids. Three main types of technology are available: dry steam, flash steam and binary cycle, depending on the characteristics of the geothermal fluid.

In dry steam plants the steam is piped directly from underground wells to the power plant, where it is directed into a turbine/generator unit. To use this plant, geothermal fluids must be in vapor state when they reach the surface. In a few cases (The Geysers in California, Larderello in Italy, Matsukawa in Japan, Kamojang and Darajat in Indonesia) the geothermal fluid is at vapor state already in the reservoir. These systems, named vapor-dominated systems, are characterized by very high temperature (exceeding $300^{\circ} \mathrm{C}$ ) 


\section{LNES 2014}

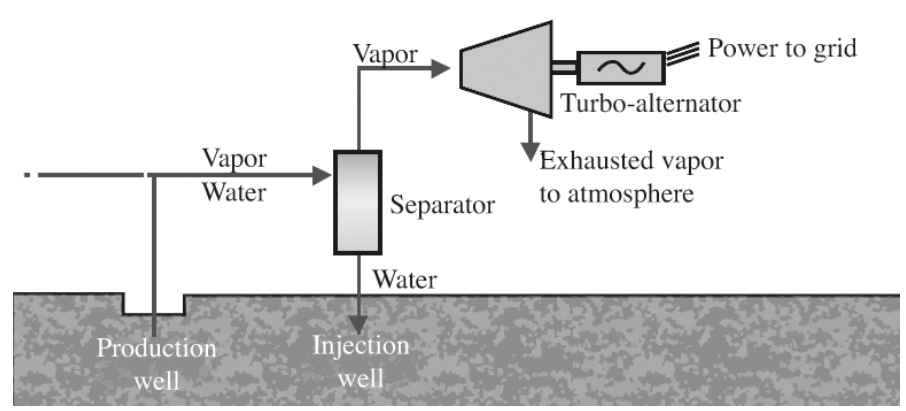

Fig. 8. - Simplified flow diagram for direct steam, atmospheric exhaust geothermal power plant.

and high production but are very localized. The most common case is that of waterdominated systems, having a mixture of liquid and vapor in the reservoir. When this mixture is reached by a well it flows upward by its own pressure. The flow results in a pressure drop. For very hot fluids, usually above $250^{\circ} \mathrm{C}$, the fluid pressure at the surface results much lower than the saturation pressure corresponding to the fluid temperature, and the mixture of water and steam is wholly vaporized before reaching the surface. In this case a dry steam plant can be used.

Steam turbines are available with either atmospheric (back-pressure) or condensing exhausts. Atmospheric exhaust units (fig. 8) are simple and cheap and quickly installed, but steam consumption (from the same inlet pressure) per kilowatt-hour produced is almost double that of a condensing unit. The steam, direct from dry steam wells or, after separation, from wet wells, is passed through a turbine and exhausted to the atmosphere. The atmospheric exhaust turbines are used as pilot plants, stand-by plants, in the case of small supplies from isolated wells, and for generating electricity from test wells during field development.

In the condensing units with condenser at the outlet of the turbine, the steam in the turbine expands to the (low) pressure value of the condenser (fig. 9). In the condenser the steam is cooled by spraying cooling water. The cooling water and condensed steam are mixed and pumped directly to the cooling tower for recirculation. Having more auxiliary equipment, the condensing units are more complex than the atmospheric exhaust units and the bigger sizes can take twice as long to construct and install. The resulting power capacity of the condensing units is, however, much higher than that of the atmospheric exhaust units. Condensing plants have an average size of $45 \mathrm{MW}_{\mathrm{e}}$. Units of $40-60 \mathrm{MW}_{\mathrm{e}}$ capacity are very common, but plants of $110 \mathrm{MW}_{\mathrm{e}}$ have also been constructed and installed.

Flash steam turbines are the most common and use very hot geothermal fluids, with temperatures higher than $180^{\circ} \mathrm{C}$. When the reservoir is reached by wells, the mixture of water and steam of liquid-dominated systems flows up through wells in the ground under its own pressure. As it flows upward, the pressure decreases and some of the hot water boils into steam. This change of state for pressure drop, called flash, gives the name to 


\section{EPJ Web of Conferences}

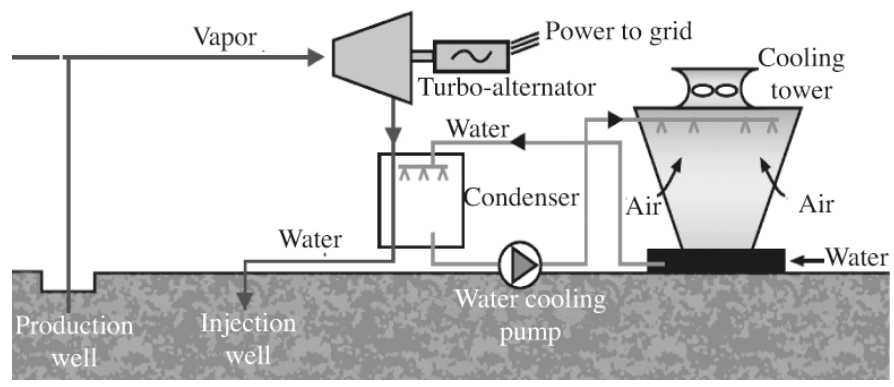

Fig. 9. - Simplified flow diagram for direct steam, condensing geothermal power plant.

the technology. The original and flashed steam is then separated from the water and used to power a turbine/generator. The liquid phase is separated by the steam and piped to be re-injected back in the subsurface. From this point on the equipment is the same of a dry steam plant, and this plant is called single-flash plant (fig. 10). Depending on the thermodynamic condition of the fluids, it could be economic to obtain a second (sometime even a third) flash from the separated fluid, producing more steam from its boiling. This double-flash steam power type of plant differ from the previous ones for the equipment required for the secondary flash. Flash steam plants have an average size of $30 \mathrm{MW}_{\mathrm{e}}$.

Generating electricity from low-to-medium temperature geothermal fluids and from the waste hot waters coming from the separators in water-dominated geothermal fields has made considerable progress since the first improvements were made in binary fluid technology. The binary cycle plants use the heat from the hot water to boil a working fluid, usually an organic fluid with a low boiling point and high vapor pressure at low temperatures when compared to steam. The working fluid is vaporized in a heat exchanger; the vapor produced drives a normal axial flow turbine, is then cooled and condensed, and the cycle begins again (fig. 11). The geothermal water is then injected back into the ground. The water and the working fluid circulate separated during the whole process, and the working fluid is keep in a closed loop, so there are little or no air emissions and the geothermal water is totally re-injected.

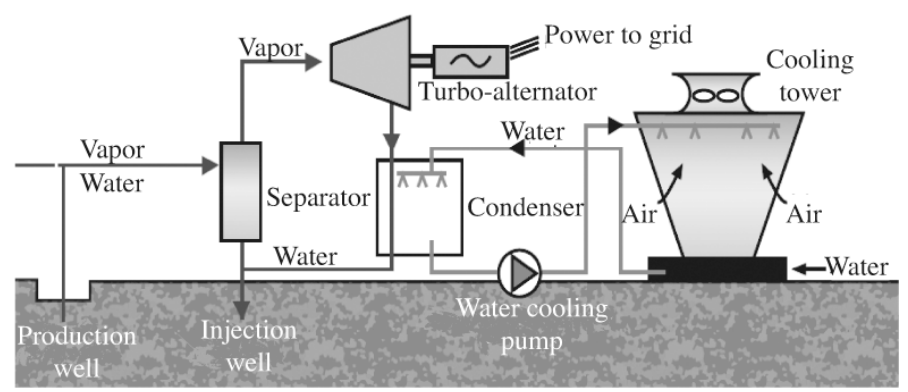

Fig. 10. - Simplified flow diagram for single flash geothermal power plant. 


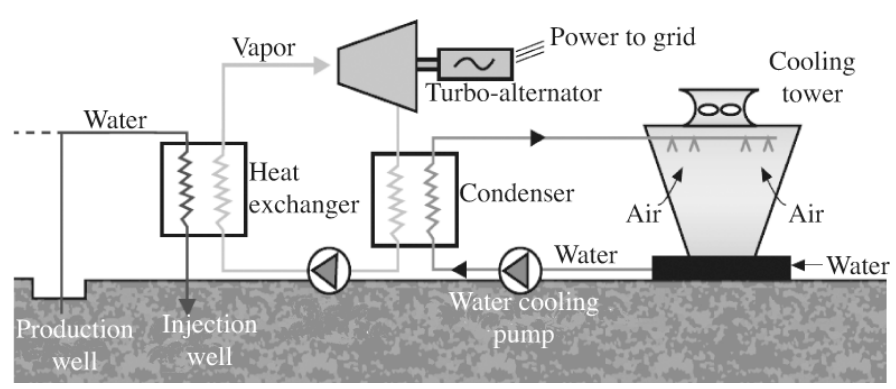

Fig. 11. - Simplified flow diagram for ORC binary geothermal power plant.

The two different categories of binary cycles commonly available, Organic Rankine Cycles (ORC) and Kalina cycles, mostly differentiate as far as the working fluid is concerned: in ORC a pure working fluid, (or seldom an azeotropic mixture) is utilized, while in Kalina cycle and Kalina derived cycles, a mixture of water and ammonia is selected. By selecting suitable secondary fluids installed binary systems utilize geothermal fluids in the temperature range $73^{\circ} \mathrm{C}$ (at Chena Hot Springs, Alaska) and $180{ }^{\circ} \mathrm{C}$. The upper limit depends on the thermal stability of the organic binary fluid, and the lower limit on technical-economic factors: below a certain temperature and depending on the air temperature at the condenser the size of the required heat exchangers would render the project uneconomical. Besides production low-to-medium temperature geothermal fluids and waste fluids, binary systems can also be used to avoid flashing of the geothermal fluids (for example, to prevent well sealing). In this case, down-hole pumps can be used to keep the fluids in a pressurised liquid state, and the energy can be extracted from the circulating fluid by means of binary units.

Binary plants are usually constructed in small modular units of a few hundred $\mathrm{kW}_{\mathrm{e}}$ to a few $\mathrm{MW}_{\mathrm{e}}$ capacity. The total size of the plant has little effect on the specific cost, as a series of standard modular units is joined together to create power-plants up to a few tens of megawatts. Their cost depends on a number of factors, but particularly on the temperature of the geothermal fluid produced, which influences the size of the turbine, heat exchangers and cooling system.

It is also possible to cascade a steam unit with a binary cycle plant, which uses the condensed steam. These combined units are under development for further optimization. Cogeneration scheme, i.e. the generation of heat (usually for district heating) and power, is also feasible, as well as hybrid plants using the geothermal source in addition to another thermal source (e.g. solar or biomass or wastes).

Any leftover water and condensed steam are injected back into the reservoir, for a sustainable use of the resource. A geothermal plant is characterized by a multitude of pipes connecting production wells to the power station for energy conversion, and pipes distributing condensed water for re-injection.

Nowadays, power production in the world have a total capacity of $11.8 \mathrm{GW}_{\mathrm{e}}$. Single flash power plants are the most used technology for geothermal power, composing $39 \%$ 


\section{EPJ Web of Conferences}

$\left(\sim 4557 \mathrm{MW}_{\mathrm{e}}\right)$ of Installed Capacity globally. Dry Steam follows at 25\% ( 3005 MW) and double flash ranks third at 19\% $(\sim 2184 \mathrm{MW})$ of global installed capacity. Lastly, binary is $14 \%(\sim 1654 \mathrm{MW})$ of global installed capacity. The last $3 \%$ of power plants are triple flash, back pressure, flash/binary hybrid, EGS (described in the Present and Future chapter), or some other geothermal technology [7].

Geothermal power production has a much shorter history than direct uses. Commercial power production commenced in Italy at the beginning of the 20th century, when Prince Ginori Conti, heir of the industrial facilities of Larderello (Tuscany, Italy) for the production of boric acid, had the idea of using the hot fluids to generate the power required by the factory. Power production in Italy increased for a while and ceased during the II World War, when the facilities were destroyed by bombs. After the war, power production steadily increased in Italy, soon accompanied by a quick growing of production in California, New Zealand and Japan. Nowadays, the largest geothermal power production area is The Geysers, California $(7.0 \mathrm{GWh} / \mathrm{a})$, followed by Cierro Prieto, Mexico (5.2 GWh/a), Tongonan, Philippines (4.8 GWh/a), Larderello, Italy (3.7 GWh/a) and Salak, Indonesia (3.0 GWh/a) [4].

Capital cost of geothermal power production plants is high, as for any other use of geothermal energy. However, since the geothermal energy is constantly provided, geothermal has a base-load production, and the Capacity Factor ( $\mathrm{CF}$, i.e. the actual produced energy with respect to the full capacity energy) is much higher than for other renewable energies, resulting in a Leveled Cost of Energy comparable to other energy sources.

Power production upfront cost can vary widely, from US\$2.8 million to US\$ 5.5 million per $\mathrm{MW}_{\mathrm{e}}$ (estimated for a reference plant of $50 \mathrm{MW}_{\mathrm{e}}$ installed capacity), depending on factors such as the geology of a country or region, quality of the resource (e.g., temperature, flow rate, chemistry), and the infrastructure in place [4]. However, geothermal power can be competitive and complement other sources of generation thanks to high capacity factors, long plant lifetimes, and the absence of recurring fuel costs. Levelized costs of energy from hydrothermal resources are usually found to be between US\$ 50 and 80 per $\mathrm{MW}_{\mathrm{e}}$. Binary plants have higher upper limits: levelized costs for new greenfield plants can be as high as US\$ 120 per $\mathrm{MW}_{\mathrm{e}}$ in the United States and US $\$ 200$ per $\mathrm{MW}_{\mathrm{e}}$ in Europe, for small plants and lower temperature resources [5].

The investment cost breakdown of utility scale geothermal power development (based on data from Iceland) shows that $35 \%$ of the total cost is related to power plant construction, and $34 \%$ to drilling. The remaining $31 \%$ is made of steam gathering system (13\%), interconnection (6\%), early development (5\%), miscellaneous (5\%) and infrastructure $(2 \%) \operatorname{costs}[4]$.

\section{4. - Geothermal project development}

To realize a geothermal plant, utilizing either shallow and deep systems, a number of activities are necessary and a geothermal project is made of essentially standard stages.

First of all, the geothermal resource is assessed through exploration, with the aim of defining the amount of heat and physicochemical characteristics of the underground. The 


\section{LNES 2014}

latter are required for the correct planning of the later activities. In parallel, especially for heat use, it is necessary to define the amount and rate of required thermal energy. After the assessment stage, the boreholes (for shallow systems) and wells are drilled and the resource is accessed and verified. The technology to be used in the plant is defined on the base of the information retrieved during the assessment and refined in the drilling stages. An environmental impact analysis is also made, as required by law almost everywhere. Eventually, facilities are built and the plant is operated and managed.

The exploration program is usually developed on a step-by-step basis: reconnaissance, pre-feasibility and feasibility. Before drawing up a complete geothermal exploration program all existing geological, hydrogeological, geophysical and geochemical data of the study area and adjacent areas must be collected. For the assessment of deep geothermal systems this pre-feasibility analysis refers to a broad area in order to eliminate the less interesting areas and concentrate on the most promising ones (reconnaissance) and prefeasibility is carried out on the chosen areas of few square kilometers. This information frequently plays an important role in defining the objectives of the geothermal exploration program and could lead to a significant reduction in costs. When all information is retrieved and the geothermal systems is roughly determined, new data are acquired to complete the picture and decide where to drill boreholes or wells (feasibility). Usually, the exploration stage is completed with the first, exploratory well drilled and a direct characterization of underground condition.

The size and budget of the exploration should be proportional to its objectives, to the importance of the resources we expect to find, and to the planned forms of utilization. The exploration schedule should be flexible, as it is often reassessed as the results come in from the various surveys; similarly the geological-geothermal model should be progressively updated and improved. These periodic re-assessments eliminate any operations that are no longer necessary and insert others, according to the results attained, in order to avoid unnecessary costs, and also to decrease the risk of error or failure in assessing and retrieving the resource. Conversely, by decreasing the risk of error the overall cost increases. The economic success of a geothermal exploration hinges on finding the proper balance between the two.

Drilling represents one of the main costs of a geothermal plant, and the number of boreholes or wells should be kept at a minimum, just necessary to satisfy the resource required by the plant to produce the demanded energy. Drilling and completion of wells are very critical operations, to be conducted with an eye on safety of the well and of the surrounding environment, and on speed, in order to decrease both operational cost and disturbance time to the neighbors. Shallow boreholes are drilled with the same technologies for fresh water wells, with similar safety precautions. The most peculiar part of shallow geothermal drilling is related to completion of geoexchangers, to secure the conductive exchange.

Deep geothermal wells uses technology similar to the rotary drilling for oil and gas. Main differences are due to the different geomechanical, physical and chemical conditions. Rocks in geothermal systems span from sedimentary rocks (as in oil and gas) to metamorphic, crystalline and volcanic rocks, usually much harder to drill. The high temperature 


\section{EPJ Web of Conferences}

affects the circulation system and the cementing procedure. Heavy mud is often used, due to the heavy load of debris to extract during the drilling. When possible, also air is used since it makes the drilling much faster and cheaper, but is used with care in formation carrying excessive water or prone to collapse. Chemical condition must be checked, especially at high temperature, to avoid productive fracture sealing, mud drying, damage to the casing or the drilling bits due to aggressive components. Blowout preventers are often used, especially in volcanic and magmatic condition where geothermal fluid may be rich of gases.

Directional drilling is used, although sub-vertical wells are common. Sometimes it may be attractive or even necessary to drill boreholes from the same platform and deviate them in different directions. Casing is usually necessary, but in hard rocks, where the risk of collapse is minimum, can be avoided. Immediately after well completion, the well is tested to obtain information regarding physicochemical condition of fluids and rocks at depth. Depending on well condition, geological and physical analyses (logs) are carried out in the well, rock and fluid samples are taken for further analyses in the labs. The most important information are temperature, depth, condition of fluid productive fractures, pressures at various depth, types of rocks and permeability, porosity, fluid content and its chemical composition. This information is used for refining the interpretation of deep geological structures, their thermal and hydraulic condition. Reservoir modeling is then carried out, to estimate potential fluid flow from the well, energy potential, and predict well performance (pressure, temperature, enthalpy of fluid).

Where wells result productive, the geothermal system is exploited. The reservoir models, after validation against field data, are then inserted in the overall reservoir simulation used for designing the geothermal field development. Well location and gathering system design must be carefully planned. Some example of consideration: wells are preferably situated higher in the landscape than the separator station and power station; if possible, the power station should be situated a little lower than the separator station, to facilitate natural fluid flow; to join multiple wells into one steam gathering system requires decision of optimum separator pressure. Optimization requires balancing of technical and economical aspects: for example, the optimum separator pressure can be calculated from a thermodynamic standpoint maximizing the generated power output, but cost considerations (capital cost of the power plant increase at decreasing steam pressure) and other constraints also dictate pressure choice. Field development comprise, after reservoir modeling, further drilling and the construction of surface plants and equipment.

\section{5. - Environmental impact}

Exploitation of geothermal energy has an impact on the environment, but it is one of the least polluting forms of energy. The degree to which geothermal exploitation affects the environment looks proportional to the scale of its exploitation and the depth of resource, and shallow geothermal systems can easily avoid to produce environmental impact by adapting the most elementary precautions. The most critical potential risk is 
thermal pollution, when the boreholes are incorrectly localized or the rate of extraction is too high. The first effect of wrong design is, however, a low efficiency of the plant, a problem that usually finds a technical solution. Electricity generation in binary cycle plants will affect the environment in the same, limited way as direct heat uses. The effects are potentially greater in the case of conventional back-pressure or condensing power plants, especially as regards air quality, but can be kept within acceptable limits. The following aspects essentially refer to deep geothermal system deployment.

Any modification to our environment must be evaluated carefully, in deference to the relevant laws and regulations (which in some countries are very severe), but also because an apparently insignificant modification could trigger a chain of events whose impact is difficult to fully assess beforehand. For example, a mere $2-3{ }^{\circ} \mathrm{C}$ increase in the temperature of a body of water as a result of discharging the waste water from a utilization plant could damage its ecosystem.

The most perceptible effect on the environment is that of drilling, whether the boreholes are shallow ones for geoexchangers or deep producing wells. Installation of a drilling rig and all the accessory equipment entails the construction of a drilling pad and access roads if they are not available. These operations will modify the surface morphology of the area and could damage local plants and wildlife. In case of blowouts of fluids from the wells, fluids can pollute surface water and air. This eventuality is nowadays well solved by the essentially constant presence of blowout preventers where high temperatures and pressures, and aggressive chemicals are anticipated. During flow tests undesirable gases may be discharged into the atmosphere, but only for a very limited time. Noise can be annoying, and drilling technology tries hard to keep noise at the lowest possible level with silencers. The best solution, indeed, is to avoid to stay too close to urban areas and to keep the drilling time as quick as possible. The impact on the environment caused by drilling is temporary, and mostly ends once drilling is completed.

Installation of the pipelines that will transport the geothermal fluids, and construction of the utilization plants, may also affect animal and plant life and the surface morphology. The landscape is modified, although in some areas the network of pipelines criss-crossing the countryside and the power plant cooling towers have become an integral part of the panorama and are indeed a famous tourist attraction in many geothermal areas. Power plant can be built in a fancy design, as in some Italian areas, or partially hidden by vegetation (usually outside the facility to ease maintenance).

Plant operation of deep, high-temperature geothermal resources, especially in volcanic and magmatic areas, may produce environmental problems. Some geothermal fluids, such as those utilized for district-heating in Iceland, are freshwaters, but this is very rare and deep geothermal fluids (steam or hot water) often contain gases such as carbon dioxide $\left(\mathrm{CO}_{2}\right)$, hydrogen sulphide $\left(\mathrm{H}_{2} \mathrm{~S}\right)$, ammonia $\left(\mathrm{NH}_{3}\right)$, methane $\left(\mathrm{CH}_{4}\right)$, and trace amounts of other gases, as well as dissolved chemicals whose concentrations usually increase with temperature. For example, sodium chloride $(\mathrm{NaCl})$, boron (B), arsenic (As) and mercury $(\mathrm{Hg})$ are a source of pollution if discharged into the environment. The waste waters from geothermal plants also have a higher temperature than the environment and therefore constitute a potential thermal pollutant. Geothermal fluids, however, may be treated 


\section{EPJ Web of Conferences}

and chemicals separated. Various processes can be adopted to reduce gas emissions, e.g. for hydrogen sulphide. Carbon dioxide is also present in the fluids used in the geothermal power plants, although much less $\mathrm{CO}_{2}$ is discharged from these plants than from fossilfuelled power stations.

Discharge of waste waters is also a potential source of chemical pollution, although the low-to-moderate temperature geothermal fluids used in most direct-use applications generally contain low levels of chemicals and the discharge of spent geothermal fluids is seldom a major problem. Spent geothermal fluids with high concentrations of chemicals such as boron, fluoride or arsenic of deep, high-temperature fluids should be treated and re-injected into the reservoir, or elements extracted for mineral use. To avoid discharge into surface waters after cooling, the waters can be cooled in special storage ponds or tanks to avoid modifying the ecosystem of natural bodies of waters (rivers, lakes and even the sea).

Extraction of large quantities of fluids from geothermal reservoirs reduce pore pressure and the land surface may tend to subside, i.e. to gradually sink. This is an irreversible phenomenon, a slow process distributed over vast areas. Over a number of years the lowering of the land surface could reach detectable levels, in some cases of the order of a few tens of centimeters and even meters, and should be monitored systematically. This effect is nowadays famous, after Wairakei in New Zealand registered a $4.5 \mathrm{~m}$ localized subsidence between 1964 and 1974: water-dominated systems such as Wairakei subside more than vapor-dominated systems. Subsidence occurrence is controlled by topographic monitoring, so far accomplished by high-resolution GPS remote control. Subsidence is prevented or reduced by re-injection of spent fluids, which also sustain the production.

The withdrawal and/or re-injection of geothermal fluids may trigger or increase the frequency of seismic events in tectonically active areas, such as those close to plate boundaries where the high temperature geothermal areas are located. In these areas the injection of fluids tends to release the accumulated tectonic stress. These small events, mostly detected by means of instrumentation, show an increase in number. Correlation studies in high temperature geothermal areas have shown, however, that the magnitude of events is not increased with respect to the maximum magnitude registered in historical time. Exploitation of hydrothermal resources is unlikely to trigger major seismic events, and so far has never been known to do so.

The noise associated with operating power generation geothermal plants is not negligible in the occasional vent discharge, although normally acceptable. At the power plant the main noise pollution comes from the cooling tower fans, the steam ejector, and the turbine 'hum'. The noise generated in direct heat applications is usually negligible.

\section{6. - Present and future}

The thermal energy present in the underground is enormous. If exploited correctly, geothermal energy could certainly assume an important role in the energy balance and small-scale geothermal resources are capable of improving energy efficiency of many applications. Today the global installed capacity of geothermal energy amounts to about 
$60 \mathrm{GW}$ worldwide with shares of $18 \%, 26 \%$, and $56 \%$ for power generation, direct use, and ground source heat pumps (GSHP), respectively. Lead markets for geothermal energy are in America, Europe and Asia [8].

The primary obstacles to geothermal deployment are the high investment cost and the risk of drilling without reaching commercially viable geothermal resources. Lowering drilling costs is a key issue for lowering up-front costs. R\&D efforts are also focussing on reducing heat exchanger costs, since design and layout of heat exchanger heavily influence the investment and operation costs of geothermal plants. Optimization of heat exchangers play a central role in geothermal binary power plants but also for direct use and GSHP applications. Regarding the risk of not finding the enough fluids to run a geothermal plant, $\mathrm{R} \& \mathrm{D}$ in exploration technology and implementation of a risk insurance fund are under consideration.

The development of Unconventional Geothermal Resources(UGR), which requires technological development to become economically productive, would increase enormously the share of utilized geothermal energy. Among UGR, research projects have focused so far to two kind of resources: Coproduced and Enhanced Geothermal Systems.

Enhanced Geothermal Systems (EGS) comprehend the development of geothermal systems where the natural flow capacity of the system is not sufficient to support adequate power production but where artificial fracturing of the system by chemical and/or hydraulic stimulation can allow production at a commercial level. The reservoirs are created to produce energy from geothermal resources that are otherwise not economical due to lack of water and/or permeability. EGS technology requires validation and deployment, cost reduction, and performance improvement. While achieving cost-competitive electricity generation from EGS is a long-term goal, in the near-term R\&D and demonstration projects will move industry along the learning curve toward technological readiness. Once technical and economic challenges for EGS are overcome, or other methods of exploiting hot rock resources become available (e.g. without fracturing the underground bedrock), geothermal deployment could be pursued wherever rock temperatures and other underground properties allow the economic sale of energy. This would mean that advanced geothermal systems could be deployed where demand for electricity and heat exist.

In coproduced resources power may be generated by the hot fluid of oil, gas, and other material harvesting processes by-products. While the quality of the resource depends on water volume and temperature, these technologies have the potential to extend the economic life of oil and gas fields. The research is primarily carried out in USA, where hundreds of thousands of oil and gas wells produce hot water concurrent with oil and gas production. It is estimated that the water produced annually by oil and gas fields could generate up to $3 \mathrm{GW}_{\mathrm{e}}$ of clean, base-load power using binary geothermal units [7]. Other uses, such as district heating and cooling, may be considered where oil and gas fields are close to urban settings. These technologies offer an opportunity to expand fossil fuels development into the renewable energy sector. Coproduced resources include also mineral recovery from geothermal fluids.

Cogeneration of heat and power (Combined Heat and Power, CHP) from deep aquifers and hybrid technology integrating geothermal to other green energy sources are important 


\section{EPJ Web of Conferences}

targets for innovative technology. The sale of heat from CHP development (e.g. for district heating) increases the economic viability of lower-temperature resources. It will be also important to further optimize cascade use of geothermal energy.

Estimated global geothermal electrical power installed capacity by 2050 amounts to $200 \mathrm{GW}_{\mathrm{e}}$, including $100 \mathrm{GW}_{\mathrm{e}}$ hydrothermal electricity capacity and $100 \mathrm{GW}_{\mathrm{e}}$ from EGS [4]. The reference scenario assumes that hot rock technology will become commercially viable soon after 2030. This power production is expected to avoid around 760 megatonnes (Mt) of $\mathrm{CO}_{2}$ emissions per year worldwide. Most of this increase is expected to happen in Pacific Asia, mainly Indonesia; the East-African Rift Valley; Central and South America; as well as in the United States, Japan, New Zealand, and Iceland.

The estimated global sum of annual geothermal heat use by 2050 amounts to 5.8 EJ (about $1600 \mathrm{TWh}$ thermal energy), removing contributions from ground source heat pumps and assuming full use of the potential of CHP generation via EGS technology [5]. Under the assumed condition, the utilization of heat from deep rock formations should theoretically become possible wherever rock temperatures and the properties of the underground allow the economic sale of energy. The largest potential for geothermal heat can be found in regions with high heat demand: Europe, China and North America.

\section{REFERENCES}

[1] Antics M., Bertani R. and Sanner B., Summary of EGC 2013 Country Update Reports on Geothermal Energy in Europe, in Proceedings of the European Geothermal Congress 2013 (2013), pp. 19.

[2] Barbier E., Renew. Sustain. Energy Rev., 6 (2002) 3.

[3] European Geothermal Energy Council, Market report 2013/2014, December 2013.

[4] Gehringer M. and Loksha V., Geothermal Handbook: planning and financing power generation, Prepared for the World Bank ,2012, pp. 149.

[5] International EnERgy Agency, Technology Roadmap: geothermal heat and power (OECD/IEA, Paris) 2011.

[6] International Energy Agency, Energy Technology Perspective 2012 (OECD/IEA, Paris) 2012.

[7] MateK B., 2013 Geothermal power: international market overview (Geothermal Energy Association) 2013, pp. 35.

[8] Sigfusson B. and Uihlein A., 2014 JRC Geothermal Energy Status Report (Publications Office of the European Union) 2015, pp. 60. 